\title{
Editorial
}

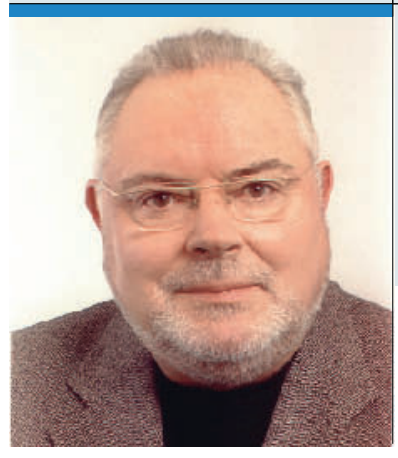

Rezeptfreie Präparate sind einerseits beliebt, andererseits aber auch ein steter Quell von Unmut.

Dr. med. Dieter Leithäuser

Chefredakteur und HNO-Arzt, Warburg

\section{OTC-Verordnung als Heinzelmännchen?}

W ie war es früher doch vordem, mit OTCRezepten so bequem! Abgewandelt gilt dieses bekannte Kölner Gedicht auch für unsere Situation in der HNO-Praxis. Vor sieben Jahren hat die damals rot-grüne Regierung rezeptfreie Arzneimittel (OTC) weitgehend aus der Erstattung in der GKV ausgeschlossen. Das sorgt auch heute noch für Debatten in unseren Sprechzimmern.

Medizinische, aber auch ökonomische Gründe bestimmen den Einsatz in der täglichen Verordnungspraxis. Eine Ärzteumfrage zeigt: $47 \%$ der Befragten sehen in rezeptfreien Präparaten durch ein günstiges Nutzen-Risiko-Verhältnis eine bessere indikationsgerechte Behandlung. 56\% der Kollegen sehen rezeptfreie Arzneimittel aus medizinischer Sicht als Mittel der Wahl. 47\% der Befragten erkennen, dass das OTC-Präparat das Arzneimittelbudget nicht belastet.

Auch wird festgestellt, dass viele Patienten häufig Fragen zu rezeptfreien Arzneien haben. 57\% der Ärzte sagen: „Ich muss immer wieder erläutern, dass die Kassen diese Präparate nur selten erstatten. "Lautstark und oft wird von Patientenseite bemängelt, dass sie mit einem grünen Rezept alles selber bezahlen müssen.
Ein typisches Beispiel für die zwei Seiten einer Medaille ist besonders in unserem Fach der Umgang mit Kombinationspräparaten vorwiegend im Ohrbereich. Da hat der Berufsverband hart gekämpft, die Kombination Antibiotikum und Kortison wieder erstattungsfähig zu machen. Aber nun ist es vielen Kollegen auch wieder nicht recht, da unser erbärmlich schmales Arzneimittelbudget durch die nicht gerade preiswerten Präparate wieder deutlich abgestuft würde. Man kann es eben nicht allen recht machen.

Wie endet das Heinzelmännchen-Gedicht? Ach dass es doch wie damals wär! Doch kommt die schöne Zeit nicht mehr.

Wir sehen uns in Mannheim.

Ihr Dieter Leithäuser
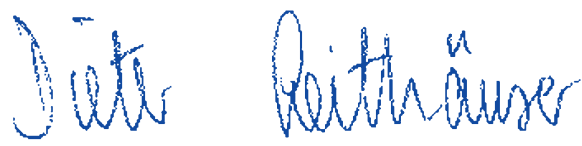